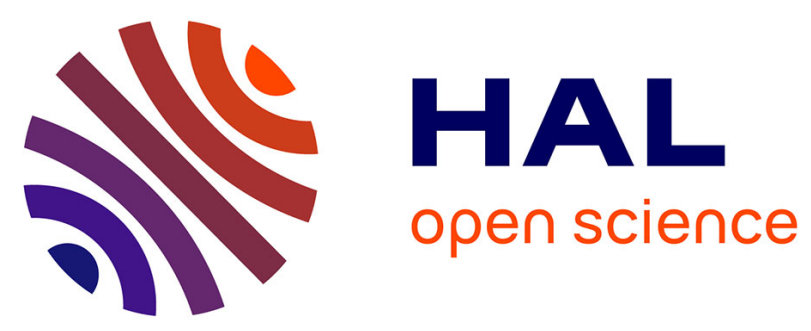

\title{
A Multiscale Characterization of Nanodielectrics: the Case of PI/Si3N4 Nanocomposite
}

\author{
M. Houssat, Christina Villeneuve-Faure, Nadine Lahoud, Jean-Pascal \\ Cambronne
}

\section{- To cite this version:}

M. Houssat, Christina Villeneuve-Faure, Nadine Lahoud, Jean-Pascal Cambronne. A Multiscale Characterization of Nanodielectrics: the Case of PI/Si3N4 Nanocomposite. 2020 IEEE 3rd International Conference on Dielectrics (ICD), Jul 2020, Valencia (virtual), Spain. pp.221-224, 10.1109/icd46958.2020.9341839 . hal-03266285

\section{HAL Id: hal-03266285 \\ https://hal.science/hal-03266285}

Submitted on 7 Jul 2021

HAL is a multi-disciplinary open access archive for the deposit and dissemination of scientific research documents, whether they are published or not. The documents may come from teaching and research institutions in France or abroad, or from public or private research centers.
L'archive ouverte pluridisciplinaire HAL, est destinée au dépôt et à la diffusion de documents scientifiques de niveau recherche, publiés ou non, émanant des établissements d'enseignement et de recherche français ou étrangers, des laboratoires publics ou privés. 


\title{
A Multiscale Characterization of Nanodielectrics: the Case of $\mathrm{PI} / \mathrm{Si}_{3} \mathrm{~N}_{4}$ Nanocomposite
}

\author{
M. Houssat, C. Villeneuve-Faure, N. Lahoud Dignat and J.P. Cambronne \\ LAPLACE, Université de Toulouse, CNRS, 118 Route de Narbonne, 31062 Toulouse Cedex 9, France
}

\begin{abstract}
Nanodielectrics are extensively investigated due to their improved properties attributed to the interphase formed between the nanoparticle and the matrix. The objective of this paper is to perform a multiscale characterization on polyimide (PI) / silicon nitride $\left(\mathrm{Si}_{3} \mathrm{~N}_{4}\right)$ nanocomposite $(\mathrm{NC})$ in order to determine the impact of the interphase on macroscale properties. NC with untreated and silane treated particles are compared. On the macroscale, breakdown strength and conductivity measurements are performed. On the nanoscale, the interphase thickness and the charge injection and decay are measured using modes derived from the Atomic Force Microscopy (AFM). Results show a higher conductivity of the interphase area compared to the matrix and a direct link between local and macroscopic properties. In addition, the interphase region, with a lower permittivity than the matrix, may present a local enhancement of the applied electric field, leading to a lower breakdown strength for $\mathrm{NC}$ materials.
\end{abstract}

\section{INTRODUCTION}

Concerning aeronautic, automobile or HVDC cable applications, polymer dielectric materials involved in electrical insulation systems undergo extreme environment conditions (high temperature, pressure, humidity....). These conditions are often combined to a higher electrical power density due to the recent more electrical systems, which lead to premature failures [1]. To improve reliability, a focus was done on the development of new materials which present improved insulating, mechanical or thermal properties. In this context, to meet these new specifications, nanocomposite (NC) materials development represents a very attractive route to upgrade polymer properties commonly used in electrical insulation systems [2].

Indeed, it was demonstrated that properties as dielectric permittivity, breakdown strength [3], partial discharges resistance [4], treeing lifetime or space charge accumulation [5] may be significantly improved by the addition of few percent by weight of nanofillers (usually lower than $10 \mathrm{wt} . \%$ ) in the polymer matrix. The main hypothesis to explain these improvements is related to the nanoparticle/matrix interphase, a region where the presence of the nanoparticle changes the matrix properties. However, physical phenomena behind these observations remain poorly understood and for a long time based on empirical rules. Various theoretical models have been introduced to describe the role of the interphase and to explain the effect of nanoscale filler materials in polymers [68]. These models predict an interphase thickness from few nanometers to few tens of nanometers depending on the fillers dimension. Recently, some attempts were done to probe interphase properties using techniques derived from Atomic Force Microscopy. Indeed, Peak-Force Quantitative NanoMechanical (PF-QNM) $[9,10]$ was used to determine the interphase thickness and Electrostatic Force Microscopy (EFM) to demonstrate that the interphase permittivity is lower than the matrix one $[10,11]$. However, underlying mechanisms explaining the interphase influence on nanodielectric properties remain poorly understood. In this context, Alhabill et al. explain the nanodielectric electrical behavior by an electron conduction in the matrix and a hole conduction in the nanoparticles interphase [12]. However, there is no local scale characterization confirming this assumption.

In this work, we have focused on the study of polyimide (PI)/silicon nitride $\left(\mathrm{Si}_{3} \mathrm{~N}_{4}\right)$ nanocomposite. Indeed, the PI has shown very attractive properties for power electronic insulation [13] and the addition of inorganic nanoparticles has shown an amelioration of the PI macroscopic properties especially at high temperatures [14]. In this study, $\mathrm{Si}_{3} \mathrm{~N}_{4}$ nanoparticles are used because they combine good electrical insulation and thermal conduction properties. Moreover, as the nanoparticle functionalization is supposed to influence the interphase properties [15], $\mathrm{Si}_{3} \mathrm{~N}_{4}$ nanoparticles treated with a silane coupling agent were also studied.

In the following, a macroscale characterization is performed in terms of conductivity and breakdown strength measurements. Moreover, a nanoscale characterization is done to determine the interphase thickness by using the PF-QNM mode and the charge injection and decay by using the Kelvin Probe Force Microscopy (KPFM) mode. Based on the obtained multiscale results, the aim of this paper is to discuss the influence of the interphase on macroscale properties.

\section{EXPERIMENTS}

\section{A. Material processing}

In this paper, $\mathrm{PI} / \mathrm{Si}_{3} \mathrm{~N}_{4}$ nanocomposite is investigated. The PI host matrix is a mix of commercial biphenyltetracarboxilic dianhydride and $\mathrm{p}$-phenylene diamine precursor monomers (BPDA-PDA) supplied as a polyamic acid (PAA) precursor solution in N-methyl-2-pyrrolidone solvent. The $\mathrm{Si}_{3} \mathrm{~N}_{4}$ is provided as spherical amorphous nanoparticles (diameter of 20 to $40 \mathrm{~nm}$ ) by SkySpring Nanomaterials Inc., Houston, USA. The nanoparticles surface functionalization is obtained by using (3-Aminopropyl) triethoxysilane (APTES, 98\%) purchased from Sigma-Aldrich.

The nanocomposite fabrication process, detailed in [9], is composed of four steps. (i) A 1 wt.\% aqueous solution 
prepared by mixing the PAA and the nanoparticles (NPs). Another solution was prepared with the addition of a silane coupling agent in order to obtain a treated nanoparticles sample. (ii) An ultra-sonication followed by a centrifugal decantation were done to reduce the size of agglomerates. (iii) The solution was spin-coated on Si wafer substrate. (iv) The imidization process was completed by a curing cycle in order to obtain $\mathrm{PI} / \mathrm{Si}_{3} \mathrm{~N}_{4}$ nanocomposite thin films.

Nanocomposite layer thickness was probed using KLATencor mechanical profilometer. A thickness of $2.3 \mu \mathrm{m}$ and $3.4 \mu \mathrm{m}$ was found for films with untreated and treated nanoparticles respectively.

For macroscale electrical measurement Metal-InsulatorSemiconductor (MIS) structures were processed. A $150 \mathrm{~nm}-$ thick gold $(\mathrm{Au})$ layer was deposited by sputtering and circular electrodes were defined by photolithography and wet etching (5 $\mathrm{mm}$ diameter for dielectric spectroscopy and $0.6 \mathrm{~mm}$ diameter for breakdown measurements). In order to eliminate the water presence effect on breakdown results, samples were all heated at $150^{\circ} \mathrm{C}$ for $48 \mathrm{~h}$ before measurements.

\section{B. Macro-scale characterization}

Dielectric spectroscopy measurements were carried out using a Novocontrol Alpha-A system. From dielectric losses results, the AC conductivity $\left(\sigma_{A C}\right)$ was obtained as expressed in the following equation [16]:

$$
\sigma_{\mathrm{AC}}=\omega \varepsilon_{0} \varepsilon^{\prime \prime}(\omega)=\sigma_{\mathrm{DC}}+\mathrm{A} \omega^{\mathrm{n}}
$$

where $\omega$ the pulsation, $\varepsilon$ " the dielectric loss factor (imaginary part of the dielectric permittivity), $A$ a temperature dependent parameter and $0.6<n<1$ is the exponent of the power law. At high frequencies, the AC conductivity linearly changes with the frequency. At low frequencies, it becomes frequency independent and a permanent value appears which corresponds to the DC (or quasi static) conductivity.

The breakdown field measurements were carried out using a Signatone S-1160 probe station equipped with micrometric positioners (temperature fixed to $25^{\circ} \mathrm{C}$ ). A DC voltage ramp of $150 \mathrm{~V} / \mathrm{s}$ was supplied using a FI 9035HT source. When the breakdown occurs, the used voltage source switches into a current source applying a short-circuit limited to $1 \mathrm{~mA}$. The dielectric breakdown field has been calculated as:

$$
\mathrm{F}_{\mathrm{br}}=\mathrm{V}_{\mathrm{br}} / \mathrm{d}
$$

where $V_{b r}$ is the measured breakdown voltage and $d$ the sample thickness. A Weibull statistical analysis on a population of 10 samples was applied for each test condition.

\section{Nano-scale characterization}

AFM measurements were performed using a Bruker Multimode 8 apparatus. The PF-QNM mode was used to probe the surface topography and map mechanical properties of nanocomposite films using a TAP525 tip (Bruker) and a contact force was tuned to obtain on all samples a deformation of around $2 \mathrm{~nm}$ over PI. This contact force was chosen as the best compromise between the spatial resolution and the sensitivity to the interphase. The Young modulus was calculated using the Derjaguin-Muller-Toropov (DMT) model [17]. To insure reliable and quantitative results a three steps calibration process was applied as detailed in [18]. (i) The static and dynamic deflection sensitivity was measured on a hard sapphire sample. (ii) The tip spring constant was determined using Sader method and Scanning Electronic Microscopy (SEM) observation. (iii) The effective tip radius was determined using polystyrene (2.7 GPa modulus) reference film. Measurements were done using $384 \times 384$ pixel, which corresponds to a pixel size of $5.2 \mathrm{~nm}$ for a $4 \mu \mathrm{m}^{2}$ scanned area.

KPFM mode was used to probe the charge injection and transport in nanocomposite films. A PtIR-coated silicon tip with a resonance frequency $f_{0}$ of $66.1 \mathrm{kHz}$, a spring constant $k$ of $2.74 \mathrm{~N} / \mathrm{m}$ and a radius of $26 \mathrm{~nm}$ was used for both injection and KPFM. Measurements were done under controlled environment (without humidity and under $\mathrm{N}_{2}$ atmosphere) [19]. The charging step was achieved in contact mode (contact force set to $20 \mathrm{nN}$ ) by applying $20 \mathrm{~V}$ to the AFM tip for $1 \mathrm{~min}$, the sample back side being grounded. After this charging step, the surface potential was measured in Amplitude Modulation KPFM mode using a $50 \mathrm{~nm}$-lift.

\section{RESULTS AND DISCUSSION}

\section{A. Macro-scale properties}

Fig. 1 shows the frequency dependence of the $\mathrm{AC}$ conductivity for neat polyimide, untreated and silane-treated nanocomposites at $25^{\circ} \mathrm{C}$. As expected, at high frequencies, the $\sigma_{A C}$ presents a linear dependence on the frequency and a quasi-similar behavior for all samples. However, at low frequencies the DC conductivity component is higher for the nanocomposite $(\mathrm{NC})$ with untreated particles compared to unfilled PI and treated NC.

Dielectric breakdown field was determined using the Weibull statistical analysis. Results at $25^{\circ} \mathrm{C}$ are reported in Table I. Results emphasize that, at room temperature, the breakdown strength is lower for nanocomposites than for the PI.

TABLE I

Breakdown strength at $25^{\circ} \mathrm{C}$ for PI and nanocomposite with and without unctionalization

\begin{tabular}{|c|c|c|c|}
\hline & PI & Untreated & Silane treated \\
\hline $\mathrm{F}_{\mathrm{br}}(\mathrm{V} / \mu \mathrm{m})$ & 653 & 612 & 505 \\
\hline
\end{tabular}

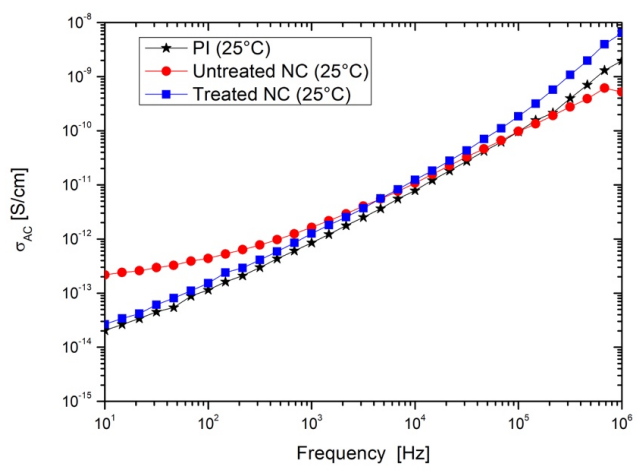

Fig. 1. The frequency dependence of the AC conductivity for neat polyimide, untreated and silane-treated nanocomposites at $25^{\circ} \mathrm{C}$ 

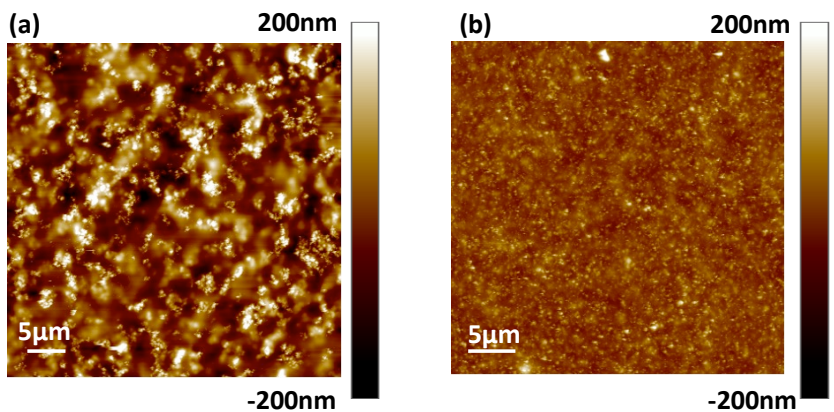

Fig. 2. Surface topography probed by PF-QNM for nanocomposites with (a) untreated and (b) treated $\mathrm{Si}_{3} \mathrm{~N}_{4}$ nanoparticles. $50 \mu \mathrm{m}$ x $50 \mu \mathrm{m}$ scan size

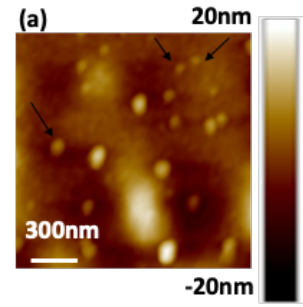

(b)
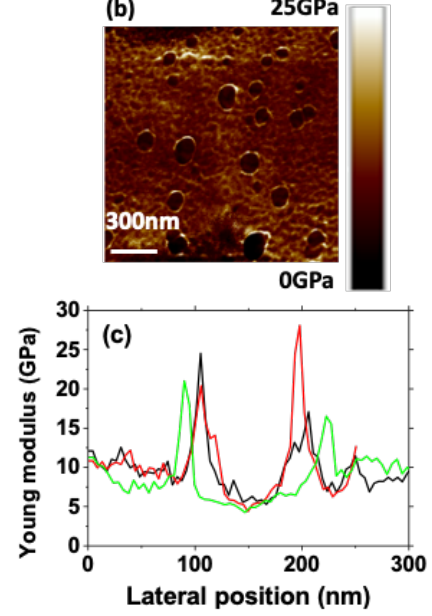

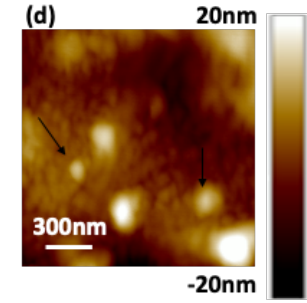

(e)
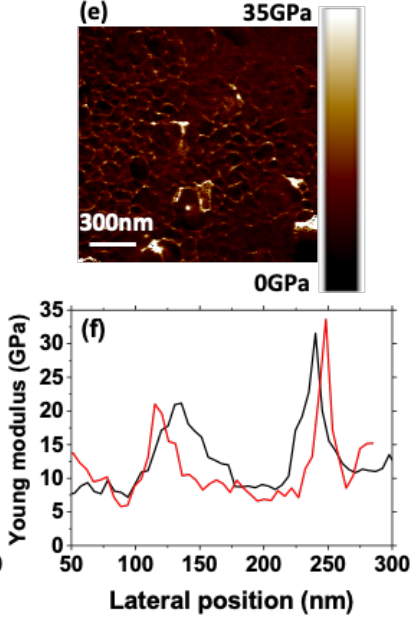

Fig. 3. (a, d) topography and (b, e) Young modulus map probed by PFQNM for untreated $(\mathrm{a}-\mathrm{c})$ and treated $(\mathrm{d}-\mathrm{f})$ nanoparticles. $(\mathrm{c}, \mathrm{f})$ Young modulus profile over protruding nanoparticles (pointed by an arrow on topography map)

\section{B. Nano-scale properties}

Surface topography mappings probed by PF-QNM for both untreated and treated $\mathrm{PI} / \mathrm{Si}_{3} \mathrm{~N}_{4}$ nanocomposites are presented in Fig. 2. For the untreated sample, agglomerated nanoparticles are visible over the surface, which induces a quite high root mean squared (rms) roughness of around 65.7 $\mathrm{nm}$. For the treated sample, nanoparticles seem well dispersed over the surface, which induces a lower rms roughness of around $23.1 \mathrm{~nm}$.

Comparison of surface morphology and Young modulus maps for nanocomposite layers with untreated (Fig. 3.a and 3.b) and treated (Fig. 3.d and 3.e) $\mathrm{Si}_{3} \mathrm{~N}_{4}$ NPs exhibits that protruding nanoparticles are visible on both cartographies. Concerning the untreated sample, Young modulus profiles over different nanoparticles protruding of around $15 \mathrm{~nm}$ height (arrows on topography maps) are depicted on Fig. 3.c. Results highlight that the Young modulus is higher in an area surrounding nanoparticles compared to the matrix. The thickness of this reinforced area is of $30 \mathrm{~nm} \pm 2 \mathrm{~nm}$ and corresponds to the interphase. The same value is obtained on protruding and partially embedded nanoparticles, which implies that topography convolution has a weak influence. Concerning the treated sample, the same behavior is observed with a Young modulus increase at the interphase. However, the interphase thickness is larger with a thickness of $48 \mathrm{~nm} \pm 6$ $\mathrm{nm}$ (Fig. 3.f). These results confirm the presence of an interphase with different properties compared to the matrix and whose thickness is higher for treated NP.

To investigate the interphase influence on charge transport, charges were locally injected using a conductive AFM tip. After the charge injection close to the NP, the surface topography remains unchanged (Fig. 4.a) whereas the surface potential is modified (Fig. 4.b) due to trapped charges. It is important to notice that the charge cloud is larger than the NP itself. Surface potential profiles for charges injected over PI (i.e. far from NP) and over the NP are depicted on Fig. 4.c. Over both the PI and the NP, the surface potential profile presents a Gaussian shape and the same maximum potential is probed. However, the profile is broader for charges injected close to the NP. Indeed, Full-Width at Half Maximum (FWHM) is $680 \mathrm{~nm}$ and $840 \mathrm{~nm}$ for the PI and the NP respectively. This implies that the NP and/or the interphase induce higher lateral charge spreading during the injection. This was confirmed by the fact that the surface potential is lower in the NP area (Fig. 4.c).

To investigated the charge dynamic after injection two parameters are defined. (i) $\mathrm{V}_{\mathrm{Mn}}$ is the maximum surface potential at a time $t$ normalized by the initial one (just after injection). (ii) The peak broadening $\Delta$ is the difference between FWHM at time $t$ and the initial one. As depicted on Fig. 4.d, the normalized maximum potential presents a higher decreasing speed for charges close to the NP compared to the PI. Moreover, the charge broadening remains small even for the NP. So, the presence of NP/interphase induces a more important charge decay. As NPs are insulating, this is probably due to a higher interphase conductivity compared to the matrix one.

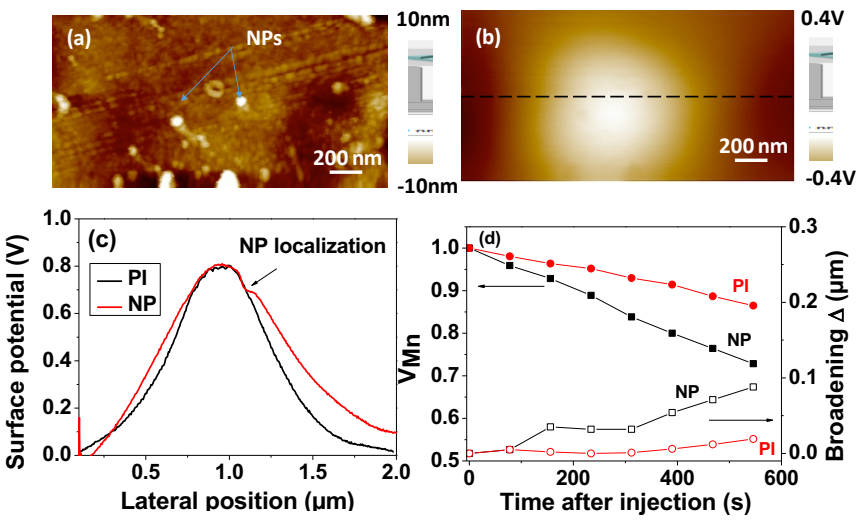

Fig. 4. (a) Surface topography and (b) surface potential probed by AM-KPFM after charge injection at $20 \mathrm{~V}$ during 1 min over untreated NP. (c) Comparison of surface potential profile after charge injection over the PI and the NP. (d) Evolution of the normalized maximum surface potential $\mathrm{V}_{\mathrm{Mn}}$ and the peak broadening with time after charge injection. 
(a) Untreated NP

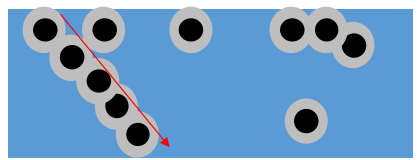

(b) Treated NP

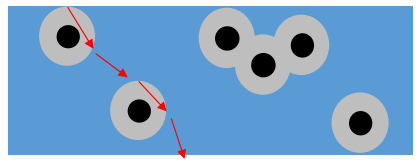

Fig. 5. The conduction behavior for (a) untreated and (b) treated NPs.

\section{Multiscale interplay phenomenon}

KPFM measurements have indicated that the presence of the $\mathrm{NP} /$ interphase modifies the charge injection and trapping. Particularly the NP/interphase induces a charge cloud spreading and a charge decay increase after injection. This could imply that the interphase presents a higher electrical conductivity than the matrix one.

Nanocomposite with untreated NPs presents a lot of aggregates and a $30 \mathrm{~nm}$-thick interphase for isolated NPs. Consequently, the conduction phenomenon may occur through the agglomerated NPs interphase as shown in Fig. 5.a. This could explain the fact that the nanocomposite with untreated NPs exhibits a DC conductivity higher than the PI one.

Nanocomposite with treated NPs presents only few aggregates with a lot of isolated NPs. The interphase area is of $48 \mathrm{~nm}$-thick, which is higher than the untreated NP interphase. Consequently, the conduction phenomenon may occur through both the NPs interphase and the PI matrix as shown in Fig. 5.b. So, the conduction is limited by the insulating PI and could explain the fact that the nanocomposite with treated NPs exhibits a DC conductivity close to the PI one.

Concerning dielectric strength, results show that the breakdown field is lower for both nanocomposites compared to the PI one. Moreover, the nanocomposite with treated NPs presents the lower breakdown field value. The only explanation of this phenomenon could be related to the interphase permittivity. Indeed, previous studies have demonstrated that the interphase dielectric permittivity is lower than the matrix one [10]. Consequently, an electric field enhancement could be localized in the interphase and this effect could be amplified in a larger interphase.

\section{CONCLUSION}

In this study, a multiscale characterization was performed in order to correlate the macroscopic properties modification to the interphase area within $\mathrm{PI} / \mathrm{Si}_{3} \mathrm{~N}_{4}$ nanocomposite materials. Both untreated and treated NPs were studied because they show different interphase dimension and properties.

Results have shown that the interphase area presents a higher conductivity than the host matrix. Depending on the NC local structure and especially in the case of the presence of aggregates, the macroscopic conductivity of the material is also increased. In addition, previous studies have shown that the interphase area presents a lower permittivity. This could generate a local field enhancement within the interphase area, which leads to a lower breakdown field for NCs compared to the neat PI.

In the following studies, a focus will be done on charge injection measurements with different polarities to separate electron and hole behaviors at a local scale. Moreover, other nanocomposite materials should be investigated as well as their multiscale behavior with temperature.

\section{REFERENCES}

[1] Y. Zhang, J. Lewiner, C. Alquié and N. Hampton, "Evidence of strong correlation between space-charge buildup and breakdown in cable insulation," IEEE Trans. Dielectr. Electr. Insul., vol. 3, p.778, 1996.

[2] A.S. Paramane and K.S. Kumar, "A review on nanocomposite based electrical insulations," Trans. Electr. Electron. Mat., vol. 17, p.239, 2016.

[3] T. Tanaka, G.C. Montanari, and R. Mulhaupt, "Polymer nanocomposites as dielectrics and electrical insulation-perspectives for processing technologies, material characterization and future applications," IEEE Trans. Dielectr. Electr. Insul., vol. 11, p.763, 2004.

[4] M. Kozako, N. Fuse, Y. Ohki, T. Okamoto and T. Tanaka, "Surface Degradation of Polyamide Nanocomposites Caused by Partial Discharges Using IEC Electrode," IEEE Trans. Dielectr. Electr. Insul., vol. 11, pp.833-839, 2004.

[5] J.K. Nelson and J. Fothergill "Internal charge behaviour of nanocomposites," Nanotechnology, vol. 15, p.586, 2004.

[6] T.J. Lewis, "Interfaces are the Dominant Feature of Dielectrics at the Nanometric Level," IEEE Trans. Dielectr. Electr. Insul., vol. 11, p.739, 2004.

[7] T. Tanaka, M. Kosako, N. Fuse and Y. Ohki, "Proposal a multi-core model for polymer nanocomposite dielectrics," IEEE Trans. Dielectr. Electr. Insul., vol. 12, p.669, 2005.

[8] T. Andritsch, R. Kochetov, P. H. F. Morshuis, and J. J. Smit, "Proposal of the polymer chain alignment model," in Annual Report Conf. Electr. Insul. Dielectr. Phen. (CEIDP), p.624, 2011.

[9] M. Houssat, N. Lahoud Dignat, J.-P. Cambronne and S. Diaham "AFM Measurements of Polyimide/Silicon Nitride Nanocomposite Interphase," IEEE Trans. Nanotechnol., vol. 17, no. 6, pp.1146-1150, 2018.

[10] M. Houssat, N. Lahoud Dignat, C. Villeneuve-Faure, J.P. Cambronne, "Effect of particles surface functionalization on interphase properties of PI/Si3N4 nanocomposite," IEEE 13th Nanotechnol. Mat. Dev. Conf. (NMDC), 2018.

[11] S. Peng, Q. Zeng, X. Yang, J. Hu and J. He, "Local dielectric property detection of the interface between nanoparticle and polymer in nanocomposite dielectrics," Scientific reports, vol. 6, p.38978, 2016.

[12] F. N. Alhabill, R. Ayoob, T. Andritsch and A.S. Vaughan, "Introducing particle interphase model for describing the electrical behaviour of nanodielectrics," Materials and Design, vol. 158, pp.62-73, 2018.

[13] M.K Ghosh and K.L. Mittal, Polyimides: Fundamentals and applications, Marcel Deker Inc., New York, 1996, 891 p.

[14] S. Diaham, F. Saysouk, M.-L. Locatelli and T. Lebey, "Huge improvements of electrical conduction and dielectric breakdown in polyimide/BN nanocomposites," IEEE Trans. Dielectr. Electr. Insul., vol. 23, pp. 2795-2803, 2016.

[15] R. K. MacCrone, J. K. Nelson, R. C. Smith, and L. S. Schadler, "The use of electron paramagnetic resonance in the probing of the nano-dielectric interface," IEEE Trans. Dielectr. Electr. Insul., vol. 15, p. 197, 2008.

[16] M. Pollak and T.H. Geballe, "Low frequency conductivity due to hopping processes in Silicon," Physical Review, vol. 122, no. 6, pp. 1742-1753, 1961.

[17] B.V. Derjaguin, V.M. Muller and Y.P. Toropov, "Effect of contact deformations on the adhesion of particles," J. Coll. Interf. Sci, vol. 53, no. 2, pp.314-326, 1975.

[18] M. Houssat, N. Lahoud Dignat, J.-P. Cambronne and S. Diaham, "AFM Measurements of Polyimide/Silicon Nitride Nanocomposite Interphase," IEEE Trans. Nanotechnol., vol. 17, no. 6, pp.1146-1150, 2018.

[19] C. Villeneuve-Faure, K. Makasheva, C. Bonafos, B. Despax, L. Boudou, P. Pons and G. Teyssedre, "Kelvin force microscopy characterization of charging effect in thin a-SiOxNy:H layers deposited in pulsed plasma enhanced chemical vapor deposition process by tuning the silicon environment," J. Appl. Phys., 113, 204102, 2013. 